\title{
Interleukin-21 receptor gene polymorphism is associated with hepatitis B virus-related hepatocellular carcinoma in Chinese patients
}

\author{
Tangyuheng Liu ${ }^{1, *}$, Mei Zhang ${ }^{1, *}$, Jiajia Song ${ }^{1, *}$, Siyue Li ${ }^{1, *}$, Jinya Zhang ${ }^{1}$, Xuejiao \\ $\mathrm{Hu}^{1}$, Zhenzhen Zhao ${ }^{1}$, Wu Peng ${ }^{1}$, Qian Wu ${ }^{1}$, Hao Bai ${ }^{1}$, Yinyu $\mathrm{Li}^{2}$, Xiaojun $\mathrm{Lu}^{1}$ and \\ Binwu Ying ${ }^{1}$ \\ ${ }^{1}$ Department of Laboratory Medicine, West China Hospital, Sichuan University, Sichuan Province, P. R. China \\ ${ }^{2}$ Department of Laboratory Medicine, Affiliated Hospital of Chengdu University, Sichuan Province, P. R. China \\ *These authors have contributed equally to this work \\ Correspondence to: Xiaojun Lu, email: luxiaojun1972@163.com \\ Binwu Ying, email: binwuying@126.com
}

Keywords: HBV; IL-21; IL-21R; JAK/STAT; SNP

Received: April 26, $2017 \quad$ Accepted: December 27, $2017 \quad$ Published: January 02, 2018

Copyright: Liu et al. This is an open-access article distributed under the terms of the Creative Commons Attribution License 3.0 (CC BY 3.0), which permits unrestricted use, distribution, and reproduction in any medium, provided the original author and source are credited.

\section{ABSTRACT}

We investigated the relationship between hepatitis B virus (HBV)-related pathogenesis and single nucleotide polymorphisms (SNPs) in interleukin-21 (IL21)-JAK-STAT signaling pathway genes. We used the high resolution melting (HRM) method to genotype five SNPs (IL-21 rs2221903, IL-21 rs4833837, IL-21 receptor (IL21R) rs2285452, JAK3 rs3008 and STAT3 rs1053023) in 546 HBV-infected patients and 353 healthy Chinese subjects. The HBV-infected patients were further divided into subgroups based on three HBV-related pathologies: chronic hepatitis B (CHB), liver cirrhosis and hepatocellular carcinoma (HCC). There were no significant differences in the genotype and allele distributions of the five SNPs between the HBV-infected patients and healthy subjects. However, patients with the IL-21R rs2285452 AA genotype were more susceptible to HBV-related HCC than those with the IL-21R rs2285452 GA/GG genotype ( $P=0.03,0 R=3.27,95 \%$ CI = 1.16-9.20). The HBsAg $^{+}$ $\mathrm{HBeAg}^{+}$anti-HBCAb+ serological marker mode was predominant among the HBVinfected patients. However, there was no association between the genotype and allelic distribution of the five SNPs with any of the eight serological marker modes.

These findings demonstrate that the IL-21R rs2285452 AA genotype increases the risk of HBV-related HCC in Chinese patients.

\section{INTRODUCTION}

Nearly 240 million people are chronically infected with hepatitis B virus (HBV) [1] and more than 686 million deaths are reported due to hepatitis B-related cirrhosis and liver cancer every year [2]. In China, approximately 90 million people are infected with HBV each year and nearly 28 million require therapeutic intervention [3].
Interleukin-21 (IL-21) is a member of the interleukin-2 family, which is primarily secreted by activated $\mathrm{CD}^{+} \mathrm{T}$ cells and natural killer T cells [4]. IL-21 promotes the proliferation and differentiation of NK cells, $\mathrm{T}$ cells and B cells; it also stimulates immunoglobulin production and induces apoptosis in both immune and non-immune cells [5]. IL-21 binds to its receptor, IL-21R, which is preferentially expressed in T-and B-lymphocytes, NK cells, certain myeloid cells and keratinocytes, but 
is absent in other tissues and solid tumors [6]. IL-21 binding to the IL-21 receptor regulates the activation and proliferation of T-, B-, and NK cells by stimulating the JAK-STAT signaling pathway [7-9]. JAK3 and STAT3 are the two key proteins that are integral to the JAK/STAT signaling pathway [10-13].

The broad immunomodulatory activity of IL-21 is critical in chronic viral infections [14]. IL-21 promotes proliferation of Tfh and Th17 lymphocytes, enhances the cytotoxicity of $\mathrm{CD}^{+} \mathrm{T}$ cells and NK cells, and induces differentiation of the B-lymphocytes into plasma cells [15]. Conversely, IL-21 inhibits dendritic cells, induces apoptosis of B cells and NK cells, and inhibits Treg cells. Based on these mechanisms, IL-21 regulates immune response to $\mathrm{HBV}$ [15]. IL-21 also plays a key regulatory role in HBV infection pathogenesis. High serum IL-21 levels are associated with a high model for end-stage liver disease (MELD) score and mortality rates [14]. In the mouse model of $\mathrm{HBV}$, IL-21 regulates specific $\mathrm{CD} 8^{+} \mathrm{T}$ - and B-lymphocyte responses that are crucial for the clearance of the viral antigens [16]. IL-21 also modulates CD4 ${ }^{+}$T-helper 2 (Th2) response that promotes HBV clearance and in vivo fibrogenesis [17]. IL-21 is also involved in the development of severe liver inflammation [17].

Host genetic factors influence the extent of HBVrelated liver injury, fibrosis, and tumorigenesis [18]. Therefore, designing effective therapeutic strategies against chronic HBV infection requires a better understanding of the host and viral mechanisms that affect HBV replication and persistence [19]. IL-21 polymorphisms are associated with systemic lupus erythematosus [20], Graves' disease [21], ischemic stroke [22], chronic hepatitis B infection [23], breast cancer [24] and thyroid cancer [25]. Moreover, polymorphisms in the IL21-JAK-STAT signaling pathway are associated with cardiovascular disease [26], breast cancer [27], renal cell carcinoma [28] and chronic myelogenous leukemia [29]. IL-21 gene polymorphisms such as rs12508721 T/C and rs2221903 A/G are also recognized as risk factors for HBV-related HCC and chronic HBV infections [30].

In this study, we investigated the association of five SNPs in the IL21-JAK-STAT signaling pathway genes with $\mathrm{HBV}$ infection and related pathology.

\section{RESULTS}

\section{Clinicopathological characteristics of study subjects and Hardy-Weinberg equilibrium (HWE) analysis}

The basic clinicopathological features of both the patients and the healthy controls in different experimental groups are shown in Table 1. There were no differences in the mean age and gender distributions between HBVinfected patients $(p=0.60)$, CHB-patients $(p=0.44)$, liver cirrhosis patients $(p=0.36)$ and HCC patients $(p=0.08)$ with their corresponding controls. Table 2 summarizes the Hardy-Weinberg equilibrium (HWE) analyses for the genotypes of the 5 SNPs in all groups. In the controls, the genotype distributions of all 5 polymorphism loci were according to HWE $(\mathrm{P}>0.05)$. However, in the HBVinfected patients, as well as the $\mathrm{CHB}$ and $\mathrm{HCC}$ patient sub-groups, $I L-21 R$ rs2285452 SNP showed deviation from HWE ( $\mathrm{p}=1.60 \mathrm{e}^{-6}, 0.002$ and $1.94 \mathrm{e}^{-8}$, respectively). Our findings support previous reports that suggest such deviations from HWE in the case group as a result of genetic drift influenced by the disease $[17,18]$.

\section{Correlation between the gene polymorphisms and $\mathrm{HBV}$ infection}

We genotyped 5 SNPs (IL-21 rs2221903, IL-21 rs4833837, IL-21R rs2285452, STAT3 rs 1053023 and JAK3 rs3008) in the HBV-infected patients and control subjects. The distribution of genotypic and allelic frequencies of the 5 SNPs is summarized in Table 3. The genotype and allele frequencies were similar in the patient and control groups for $I L-21 \mathrm{rs} 2221903$ ( $P=0.83$ and 0.67, respectively; OR $=0.86,95 \% \mathrm{CI}=0.40-1.82), I L-21 \mathrm{rs} 4833837(P=0.80$ and 0.49 , respectively; $\mathrm{OR}=1.31,95 \% \mathrm{CI}=0.61-2.77)$, $I L-21 R$ rs2285452 ( $P=0.25$ and 0.68 , respectively; OR $=0.93,95 \% \mathrm{CI}=0.68-1.29)$, STAT3 $\mathrm{rs} 1053023(P=1.00$ and 0.96 , respectively; $\mathrm{OR}=1.01,95 \% \mathrm{CI}=0.77-1.31)$ and $J A K 3 \mathrm{rs} 3008(P=0.32$ and 0.54 , respectively; OR $=1.08$, $95 \% \mathrm{CI}=0.85-1.37)$ polymorphisms. Moreover, there were no significant differences between the patient and controls groups in the additive, dominant and recessive models for the 5 candidate SNPs as shown in Table 4.

\section{Correlation between the gene polymorphisms and different $\mathrm{HBV}$-related pathologies}

Next, we investigated the correlation between the 5 SNPs and different HBV-related pathologies such as CHB, cirrhosis and HCC (Tables 5-7). The allele and genotype distributions of the candidate 5 SNPs were similar in the CHB (Table 5) and the cirrhosis groups of HBV-infected patients (Table 6) relative to the control groups. However, $\mathrm{HBV}$-infection was significantly different in the AA, GA and GG genotypes of the $I L-21 R$ rs2285452 SNP in the HCC and control groups ( $p=0.007$; Table 7$)$. However, we failed to confirm the protective and the risk genotypes. The data for the subgroup analysis based on the different genetic models is shown in Table 4. In the recessive model, subjects carrying the $I L-21 R$ rs 2285452 AA genotype were associated with greater risk (2.27 fold) in developing HCC than the combined genotypes of GA and GG carriers (AA vs. GA + GG; $P=0.03, \mathrm{OR}=3.27,95 \% \mathrm{CI}=1.16$ 9.20). However, the additive model analysis of the $I L-21 R$ rs2285452 SNP (AA vs. GA vs. GG; $P=0.97, \mathrm{OR}=1.00$, $95 \% \mathrm{CI}=0.67-1.53)$ showed no differences for $\mathrm{CHB}$ and cirrhosis subgroups vs. control group (Table 4). 
Table 1: Basic characteristics of patients and controls

\begin{tabular}{lccccc}
\hline Groups & $\mathbf{n}$ & Males/females & $\boldsymbol{p}$ & Age & \multicolumn{1}{c}{ A $^{2}$} \\
\hline Patients & 546 & $388 / 158(2.46)$ & $0.60^{\mathrm{a}}$ & $31.05 \pm 13.65$ & $0.40^{\mathrm{a}}$ \\
CHB & 302 & $218 / 84(2.60)$ & $0.44^{\mathrm{b}}$ & $34.50 \pm 11.15$ & $0.79^{\mathrm{b}}$ \\
Cirrhosis & 115 & $85 / 30(2.83)$ & $0.36^{\mathrm{c}}$ & $33.31 \pm 11.29$ & $0.50^{\mathrm{c}}$ \\
HCC & 129 & $100 / 29(6.59)$ & $0.08^{\mathrm{d}}$ & $32.69 \pm 12.12$ & $0.60^{\mathrm{d}}$ \\
Controls & 353 & $245 / 108(2.27)$ & & $34.76 \pm 13.30$ & \\
\hline
\end{tabular}

a: Patients vs Controls; ${ }^{\text {b: }}$ CHB vs Controls; ${ }^{c}$ : Cirrhosis vs Controls; ${ }^{\mathrm{d}}$ : HCC vs Controls.

Table 2: The results of HWE analyses for the genotypes of 5 SNPs

\begin{tabular}{llccccc}
\hline Groups & $\mathbf{n}$ & \multicolumn{5}{c}{$\boldsymbol{p}$} \\
\cline { 3 - 6 } & & $\mathbf{r s 2 2 2 1 9 0 3}$ & $\mathbf{r s 4 8 3 3 8 3 7}$ & $\mathbf{r s 2 2 8 5 4 5 2}$ & $\mathbf{r s 1 0 5 3 0 2 3}$ & $\mathbf{r s 3 0 0 8}$ \\
\hline Patients & 546 & 0.954 & 0.873 & $1.60 \mathrm{e}^{-6}$ & 0.544 & 0.546 \\
CHB & 302 & 0.909 & 0.182 & 0.002 & 0.211 & 0.822 \\
Cirrhosis & 115 & 0.148 & 0.054 & 0.599 & 0.413 & 0.920 \\
HCC & 129 & 0.075 & 0.832 & $1.94 \mathrm{e}^{-8}$ & 0.693 & 0.368 \\
Controls & 353 & 0.503 & 0.850 & 0.191 & 0.533 & 0.160 \\
\hline
\end{tabular}

\section{Correlation analysis between the gene polymorphisms and the serological marker mode of $\mathrm{HBV}$}

The serological markers (HBsAg, anti-HBs $\mathrm{Ab}, \mathrm{HBeAg}$, anti-HBe $\mathrm{Ab}$ and anti-HBc $\mathrm{Ab}$ ) are used to estimate the progression and outcomes of $\mathrm{HBV}$ infection. Therefore, we tested the serological markers of 257 randomly selected CHB patients and analyzed the relationship between candidate SNP genotypes and the status of the serological markers (Table 8). We identified eight serological modes. The most represented serological mode in the $\mathrm{HBV}$-infected patients was $\mathrm{HBsAg}^{+} \mathrm{HBeAg}^{+}$ anti-HBc ${ }^{+}(n=44.75 \%)$, followed by $\mathrm{HBsAg}^{+}$anti-HBe ${ }^{+}$ anti-HBc ${ }^{+}(\mathrm{n}=37.35 \%)$, and $\mathrm{HBsAg}^{+} \mathrm{HBeAg}^{+}$anti-HBe ${ }^{+}$ anti-HBc ${ }^{+}(n=8.2 \%)$. Among the $257 \mathrm{CHB}$ patients, $139(54.09 \%)$ were $\mathrm{HBeAg}^{+}$. As shown in Table 9, the genotype and allele frequencies in the 8 serological marker modes were similar for $I L-21$ rs2221903 ( $p=0.46$ and 0.19 , respectively), $I L-21 \mathrm{rs} 4833837$ ( $p=0.36$ and 0.21 , respectively), STAT3 rs 1053023 ( $p=0.81$ and 0.95, respectively), $J A K 3 \mathrm{rs} 3008$ ( $p=0.79$ and 0.94 , respectively) SNPs. However, the distribution of the $I L-21 R$ rs 2285452 alleles and genotypes showed significant differences among the 8 serological marker modes $(p=0.00$ and $\mathrm{p}=0.00$, respectively).

\section{DISCUSSION}

In our study, we examined the association of 5 SNPs in the IL-21-JAK-STAT signaling pathway genes (IL-21 rs2221903, IL-21 rs4833837, IL-21R rs2285452, STAT3 rs1053023, and $J A K 3$ rs3008) with HBV infection-related pathogenesis in a Chinese population.

There was no significant association between HBV infection and all the five SNPs based on our analysis of the patient and control subjects. However, in the recessive model, the $I L-21 R$ rs2285452 AA genotype was associated with HBV-related HCC $(\mathrm{P}=0.03)$. The subjects with the $I L-21 R$ rs2285452 AA genotype were at a higher risk (2.27 times) for HBV-related HCC than subjects with $I L-21 R$ rs2285452 GA/GG genotypes. This implied that $I L-21 R$ was a susceptibility gene associated with the occurrence and progression of $\mathrm{HBV}$ and that the patients with the heterozygous $I L-21 R$ rs 2285452 AA genotype were at a greater risk for developing $\mathrm{HCC}$.

IL-21 modulates both T-cell and B-cell responses, which are critical in the immune response related to the pathogenesis of various diseases like type1 diabetes, autoimmune systemic lupus erythematosus (SLE) and multiple sclerosis [31], including chronic HBV infections $[13,23]$. Previous reports showed that SNPs in the $I L-21$ gene, such as rs907715 and rs2221903, increased susceptibility to Grave's disease [32, 33] and systemic lupus erythematosus (SLE) in the Europeans and Americans [34, 35], as well as the Chinese [20, 36, 37]. Moreover, IL-21 rs4833837 SNP was identified as a protective factor for psoriasis [13]. Although most IL-21 gene-related SNPs were related to autoimmune diseases, the $I L-21$ rs2221903 genotype AG and allele $\mathrm{G}$ was identified as a protective factor against chronic HBV and the $I L-21$ rs2221903 genotype AA and allele A 
Table 3: Comparison of genotype and allele frequencies between patient and control groups

\begin{tabular}{|c|c|c|c|c|c|c|c|c|c|c|c|c|}
\hline \multirow[t]{2}{*}{ Gene } & \multirow[t]{2}{*}{ SNP } & \multirow[t]{2}{*}{ Group } & \multicolumn{2}{|c|}{ Allele } & \multicolumn{2}{|c|}{ Allele n (\%) } & \multirow[t]{2}{*}{ OR (95\%CI) } & \multirow[t]{2}{*}{$P$} & \multicolumn{3}{|c|}{ Genotype n (\%) } & \multirow[t]{2}{*}{$P$} \\
\hline & & & 1 & 2 & 1 & 2 & & & 11 & 12 & 22 & \\
\hline \multirow[t]{2}{*}{ IL-21 } & rs 2221903 & Patient & A & G & $961(88.00)$ & $131(12.00)$ & $0.86[0.40-1.82]$ & 0.67 & $423(77.47)$ & $115(21.06)$ & $8(1.47)$ & 0.83 \\
\hline & & Control & & & $619(87.68)$ & $87(12.32)$ & & & $270(76.49)$ & 79 (22.38) & $4(1.13)$ & \\
\hline \multirow[t]{2}{*}{ IL-21 } & rs 4833837 & Patient & A & G & 965 (88.37) & $127(11.63)$ & $1.31[0.61-2.77]$ & 0.49 & $426(78.02)$ & $113(20.70)$ & $7(1.28)$ & 0.80 \\
\hline & & Control & & & $617(87.39)$ & $89(12.61)$ & & & $270(76.49)$ & $77(21.81)$ & $6(1.70)$ & \\
\hline \multirow[t]{2}{*}{ IL-21R } & $\mathrm{rs} 2285452$ & Patient & A & G & $117(10.71)$ & 975 (89.29) & $0.93[0.68-1.29]$ & 0.68 & $17(3.11)$ & $83(15.20)$ & 446 (81.69) & 0.25 \\
\hline & & Control & & & $80(11.33)$ & $626(88.67)$ & & & $7(1.98)$ & $66(18.70)$ & $280(79.32)$ & \\
\hline \multirow[t]{2}{*}{ STAT3 } & rs 1053023 & Patient & A & G & 742 (67.95) & $350(32.05)$ & $1.01[0.77-1.31]$ & 0.96 & $249(45.60)$ & 244 (44.69) & $53(9.71)$ & 1.00 \\
\hline & & Control & & & $482(68.27)$ & $224(31.73)$ & & & $162(45.89)$ & $158(44.76)$ & $33(9.35)$ & \\
\hline \multirow[t]{2}{*}{ JAK3 } & rs3008 & Patient & $\mathrm{T}$ & $\mathrm{C}$ & $489(44.78)$ & $603(55.22)$ & $1.08[0.85-1.37]$ & 0.54 & $163(29.86)$ & $277(50.73)$ & $106(19.41)$ & 0.32 \\
\hline & & Control & & & $395(55.95)$ & $311(44.05)$ & & & $117(33.14)$ & $161(45.61)$ & $75(21.25)$ & \\
\hline
\end{tabular}

$\mathrm{CI}=$ confidence interval, $\mathrm{OR}=$ odds ratio, $\mathrm{SNP}=$ single nucleotide polymorphism.

Table 4: Association between IL-21-JAK/STAT Signaling Pathway polymorphisms and the risk of infecting with hepatitis $B$ virus

\begin{tabular}{|c|c|c|c|c|c|c|c|c|}
\hline \multirow[t]{2}{*}{$\overline{\text { Group }}$} & \multirow[t]{2}{*}{ Gene } & \multirow[t]{2}{*}{ SNP } & \multicolumn{2}{|c|}{ Additive model } & \multicolumn{2}{|c|}{ Recessive model } & \multicolumn{2}{|c|}{ Dominant model } \\
\hline & & & OR(95\%CI) & $P$ & OR(95\%CI) & $P$ & OR(95\%CI) & $P$ \\
\hline \multirow{5}{*}{$\begin{array}{l}\text { Patient } \\
\text { Vs } \\
\text { Control }\end{array}$} & IL-21 & $\mathrm{rs} 2221903 \mathrm{~A}>\mathrm{G}$ & $0.97[0.73-1.30]$ & 0.86 & $0.77[0.23-2.58]$ & 0.77 & $1.06[0.77-1.45]$ & 0.73 \\
\hline & IL-21 & rs $4833837 \mathrm{~A}>\mathrm{G}$ & $0.91[0.68-1.22]$ & 0.53 & $1.33[0.40-4.00]$ & 0.61 & $1.09[0.79-1.50]$ & 0.59 \\
\hline & IL-21R & $\mathrm{rs} 2285452 \mathrm{G}>\mathrm{A}$ & $1.10[0.98-1.40]$ & 0.70 & $0.86[0.61-1.20]$ & 0.38 & $1.59[0.65-3.87]$ & 0.30 \\
\hline & STAT3 & $\mathrm{rs} 1053023 \mathrm{~A}>\mathrm{G}$ & $1.02[0.83-1.25]$ & 0.88 & $0.96[0.61-1.52]$ & 0.86 & $0.99[0.76-1.29]$ & 0.93 \\
\hline & JAK3 & $\mathrm{rs} 3008 \mathrm{C}>\mathrm{T}$ & $1.03[0.85-1.24]$ & 0.76 & $1.12[0.80-1.56]$ & 0.50 & $0.86[0.64-1.14]$ & 0.30 \\
\hline \multirow{5}{*}{$\begin{array}{l}\text { CHB } \\
\text { Vs } \\
\text { Control }\end{array}$} & IL-21 & rs $2221903 A>G$ & $0.84[0.59-1.20]$ & 0.32 & $1.11[0.25-5.00]$ & 1.00 & $1.22[0.84-1.78]$ & 0.30 \\
\hline & IL-21 & rs $4833837 A>G$ & $0.87[0.62-1.21]$ & 0.41 & $0.85[0.27-2.67]$ & 0.79 & $1.22[0.84-1.76]$ & 0.31 \\
\hline & IL-21R & rs $2285452 \mathrm{G}>\mathrm{A}$ & $1.12[0.80-1.57]$ & 0.50 & $0.82[0.55-1.21]$ & 0.31 & $1.35[0.48-3.75]$ & 0.57 \\
\hline & STAT3 & rs $1053023 A>G$ & $0.90[0.71-1.15]$ & 0.40 & $1.31[0.75-2.30]$ & 0.34 & $1.10[0.81-1.49]$ & 0.57 \\
\hline & JAK3 & $\mathrm{rs} 3008 \mathrm{C}>\mathrm{T}$ & $0.96[0.78-1.20]$ & 0.72 & $1.21[0.82-1.79]$ & 0.33 & $0.95[0.69-1.33]$ & 0.78 \\
\hline \multirow{5}{*}{$\begin{array}{l}\text { Cirrhosis } \\
\text { Vs } \\
\text { Control }\end{array}$} & IL-21 & $\mathrm{rs} 2221903 \mathrm{~A}>\mathrm{G}$ & $1.16[0.28-10.49]$ & 0.10 & $1.31[0.15-11.81]$ & 1.00 & $0.65[0.84-1.78]$ & 0.07 \\
\hline & IL-21 & rs $4833837 A>G$ & $1.26[0.82-1.94]$ & 0.30 & $1.01[1.00-1.03]$ & 0.34 & $0.70[0.44-1.12]$ & 0.14 \\
\hline & IL-21R & $\mathrm{rs} 2285452 \mathrm{G}>\mathrm{A}$ & $0.96[0.61-1.51]$ & 0.87 & $1.21[0.68-1.86]$ & 0.66 & $0.43[0.05-3.56]$ & 0.67 \\
\hline & STAT3 & rs $1053023 A>G$ & $1.22[0.89-1.66]$ & 0.22 & $0.59[0.32-1.11]$ & 0.10 & $0.88[0.57-1.34]$ & 0.54 \\
\hline & JAK3 & $\mathrm{rs} 3008 \mathrm{C}>\mathrm{T}$ & $1.19[0.89-1.60]$ & 0.23 & $0.88[0.53-1.45]$ & 0.62 & $0.71[0.44-1.14]$ & 0.16 \\
\hline \multirow{5}{*}{$\begin{array}{l}\text { HCC } \\
\text { Vs } \\
\text { Control }\end{array}$} & IL-21 & rs $2221903 A>G$ & $0.97[0.63-1.50]$ & 0.90 & $0.36[0.09-1.45]$ & 0.22 & $1.16[0.71-1.90]$ & 0.55 \\
\hline & IL-21 & rs $4833837 \mathrm{~A}>\mathrm{G}$ & $0.72[0.45-1.16]$ & 0.17 & $2.21[0.26-18.56]$ & 0.68 & $1.35[0.81-2.23]$ & 0.27 \\
\hline & IL-21R & rs $2285452 G>A$ & $1.00[0.67-1.53]$ & 0.97 & $3.27[1.16-9.20]$ & 0.03 & $0.75[0.44-1.27]$ & 0.28 \\
\hline & STAT3 & $\mathrm{rs} 1053023 \mathrm{~A}>\mathrm{G}$ & $1.12[0.82-1.52]$ & 0.48 & $0.85[0.44-1.64]$ & 0.62 & $1.14[0.76-1.71]$ & 0.53 \\
\hline & JAK3 & $\mathrm{rs} 3008 \mathrm{C}>\mathrm{T}$ & $0.95[0.71-1.26]$ & 0.72 & $1.28[0.82-2.00]$ & 0.27 & $0.85[0.51-1.41]$ & 0.53 \\
\hline
\end{tabular}

$\mathrm{CI}=$ confidence interval, $\mathrm{OR}=$ odds ratio, $\mathrm{SNP}=$ single nucleotide polymorphism. 
Table 5: Comparison of genotype and allele frequencies between CHB and control groups

\begin{tabular}{|c|c|c|c|c|c|c|c|c|c|c|c|c|}
\hline \multirow[t]{2}{*}{ Gene } & \multirow[t]{2}{*}{ SNP } & \multirow[t]{2}{*}{ Group } & \multicolumn{2}{|c|}{ allele } & \multicolumn{2}{|c|}{ Allele n (\%) } & \multirow[t]{2}{*}{ OR $(95 \% C I)$} & \multirow[t]{2}{*}{$P$} & \multicolumn{3}{|c|}{ Genotype n (\%) } & \multirow[t]{2}{*}{$P$} \\
\hline & & & 1 & 2 & 1 & 2 & & & 11 & 12 & 22 & \\
\hline \multirow[t]{2}{*}{ IL-21 } & \multirow[t]{2}{*}{ rs2221903 } & $\mathrm{CHB}$ & A & G & $542(89.74)$ & $62(10.26)$ & \multirow{2}{*}{$1.23[0.87-1.74]$} & \multirow{2}{*}{0.24} & $234(80.47)$ & $56(18.54)$ & $3(0.99)$ & \multirow{2}{*}{0.47} \\
\hline & & Control & & & $238(24.33)$ & $87(12.32)$ & & & $270(76.49)$ & $79(22.38)$ & $4(1.13)$ & \\
\hline \multirow[t]{2}{*}{ IL-21 } & \multirow[t]{2}{*}{ rs4833837 } & CHB & A & G & $537(88.91)$ & $67(11.09)$ & \multirow{2}{*}{$1.16[0.83-1.62]$} & \multirow{2}{*}{0.40} & $241(79.80)$ & $55(18.21)$ & $6(1.99)$ & \multirow{2}{*}{0.51} \\
\hline & & Control & & & $617(87.39)$ & $89(12.61)$ & & & $270(76.49)$ & $77(21.81)$ & $6(1.70)$ & \\
\hline \multirow[t]{2}{*}{ IL-21R } & \multirow[t]{2}{*}{ rs 2285452} & CHB & A & G & $61(10.10)$ & $543(89.90)$ & \multirow{2}{*}{$0.88[0.62-1.25]$} & \multirow{2}{*}{0.47} & $8(2.65)$ & $45(14.90)$ & $249(82.45)$ & \multirow{2}{*}{0.39} \\
\hline & & Control & & & $80(11.33)$ & $626(88.67)$ & & & $7(1.98)$ & $66(18.70)$ & $280(79.32)$ & \\
\hline \multirow[t]{2}{*}{ STAT3 } & \multirow[t]{2}{*}{ rs 1053023} & $\mathrm{CHB}$ & A & G & $425(70.36)$ & $179(29.64)$ & \multirow{2}{*}{$1.10[0.87-1.40]$} & \multirow{2}{*}{0.41} & $145(48.01)$ & $135(44.70)$ & $22(7.29)$ & \multirow{2}{*}{0.61} \\
\hline & & Control & & & $482(68.27)$ & $224(31.73)$ & & & $162(45.89)$ & $158(44.76)$ & $33(9.35)$ & \\
\hline \multirow[t]{2}{*}{ JAK3 } & \multirow[t]{2}{*}{ rs 3008} & $\mathrm{CHB}$ & $\mathrm{T}$ & $\mathrm{C}$ & $344(56.95)$ & $260(43.05)$ & \multirow{2}{*}{$0.96[0.77-1.20]$} & \multirow{2}{*}{0.72} & $97(32.12)$ & $150(49.67)$ & $55(18.21)$ & \multirow{2}{*}{0.5} \\
\hline & & Control & & & $395(55.95)$ & $311(44.05)$ & & & $117(33.14)$ & $161(45.61)$ & $75(21.25)$ & \\
\hline
\end{tabular}

$\mathrm{CI}=$ confidence interval, $\mathrm{OR}=$ odds ratio, $\mathrm{SNP}=$ single nucleotide polymorphism.

Table 6: Comparison of genotype and allele frequencies between cirrhosis and control groups

\begin{tabular}{|c|c|c|c|c|c|c|c|c|c|c|c|c|}
\hline \multirow[t]{2}{*}{ Gene } & \multirow[t]{2}{*}{ SNP } & \multirow[t]{2}{*}{ Group } & \multicolumn{2}{|c|}{ Allele } & \multicolumn{2}{|c|}{ Allele n (\%) } & \multirow{2}{*}{$\begin{array}{c}\text { OR } \\
(95 \% \mathrm{CI})\end{array}$} & \multirow[t]{2}{*}{$P$} & \multicolumn{3}{|c|}{ Genotype n (\%) } & \multirow[t]{2}{*}{$P$} \\
\hline & & & 1 & 2 & 1 & 2 & & & 11 & 12 & 22 & \\
\hline \multirow[t]{2}{*}{ IL-21 } & \multirow[t]{2}{*}{ rs 2221903} & Cirrhosis & A & G & $192(83.48)$ & $38(16.52)$ & \multirow{2}{*}{$0.48[0.15-1.55]$} & \multirow{2}{*}{0.22} & $78(67.83)$ & $36(31.30)$ & $1(0.87)$ & \multirow{2}{*}{0.15} \\
\hline & & Control & & & $619(87.68)$ & $87(12.32)$ & & & $270(76.49)$ & $79(22.38)$ & $4(1.13)$ & \\
\hline \multirow[t]{2}{*}{ IL-21 } & \multirow[t]{2}{*}{ rs 4833837} & Cirrhosis & A & G & $195(84.78)$ & $35(15.22)$ & \multirow{2}{*}{$1.70[0.52-5.57]$} & \multirow{2}{*}{0.38} & $80(69.57)$ & $35(30.43)$ & - & \multirow{2}{*}{0.07} \\
\hline & & Control & & & $617(87.39)$ & $89(12.61)$ & & & $270(76.49)$ & $77(21.81)$ & $6(1.70)$ & \\
\hline \multirow[t]{2}{*}{ IL-21R } & \multirow[t]{2}{*}{ rs 2285452} & Cirrhosis & A & G & $27(11.74)$ & $203(88.26)$ & \multirow{2}{*}{$1.16[0.68-1.97]$} & \multirow{2}{*}{0.60} & $1(0.87)$ & $25(21.74)$ & 89 (77.39) & \multirow{2}{*}{0.58} \\
\hline & & Control & & & $80(11.33)$ & $626(88.67)$ & & & $7(1.98)$ & $66(18.70)$ & $280(79.32)$ & \\
\hline \multirow[t]{2}{*}{ STAT3 } & \multirow[t]{2}{*}{ rs 1053023} & Cirrhosis & A & G & $147(63.91)$ & 83 (36.09) & \multirow{2}{*}{$0.95[0.62-1.46]$} & \multirow{2}{*}{0.83} & $49(42.61)$ & $49(42.61)$ & $17(14.78)$ & \multirow{2}{*}{0.26} \\
\hline & & Control & & & $482(68.27)$ & $224(31.73)$ & & & $162(45.89)$ & $158(44.76)$ & $33(9.35)$ & \\
\hline \multirow[t]{2}{*}{ JAK3 } & \multirow[t]{2}{*}{ rs3008 } & Cirrhosis & $\mathrm{T}$ & $\mathrm{C}$ & $118(51.30)$ & $112(48.70)$ & \multirow{2}{*}{$1.28[0.86-1.92]$} & \multirow{2}{*}{0.23} & $30(26.09)$ & $58(50.43)$ & $27(23.48)$ & \multirow{2}{*}{0.37} \\
\hline & & Control & & & $395(55.95)$ & $311(44.05)$ & & & $117(33.14)$ & $161(45.61)$ & $75(21.25)$ & \\
\hline
\end{tabular}

$\mathrm{CI}=$ confidence interval, $\mathrm{OR}=$ odds ratio, $\mathrm{SNP}=$ single nucleotide polymorphism.

was identified as a risk factor in chronic HBV infections [38]. We postulate that IL-21 modulates B-lymphocytes, which play a significant role in neutralizing and removing circulating $\mathrm{HBV}$ by producing effective antibodies [39]. In our study, the two SNPs in the $I L$ 21 gene, rs2221903 and rs4833837, were located in the intron and the 3 rd exon of the $I L-21$ gene, respectively. However, they were not associated with HBV infection. The varying results between our study and others may be due to the differences in sample sizes and the study populations.

In the present study, we demonstrated that the $I L$ $21 R$ rs2285452 SNP was associated with HBV-related HCC. The $I L-21 R$ rs 2285452 polymorphism is located in the 3'-UTR. The patients with the AA genotype of $I L-21 R$ rs2285452 show higher risk of HBV-related HCC than those with the AG/GG genotype. In a previous study, the $I L-21 R$ rs2285452 polymorphism showed differential genotype distribution in Hashimoto's thyroiditis (HT) and control subjects [40]. Moreover, the $I L-21$ rs2221903 and $I L-21 R$ rs3093301 polymorphisms were associated with chronic HBV infection, an interactive role of IL21R rs3093301 CC with IL21 rs2221903 in inducing the elevation of IL-21 and IgE production in the HBV patients, thereby suggesting that the SNPs in the $I L$ 21 and $I L-21 R$ genes influence the susceptibility and persistence of HBV by affecting serum IL-21 and IgE levels [38].

Our finding suggests that the SNPs in $I L-21 R$ play an important role in HBV infection and HBV-related HCC. We postulate that IL-21 induces HBV-related HCC cells. On the other hand, IL-21 probably enhances the 
Table 7: Comparison of genotype and allele frequencies between $\mathrm{HCC}$ and control groups

\begin{tabular}{|c|c|c|c|c|c|c|c|c|c|c|c|c|}
\hline \multirow[t]{2}{*}{ Gene } & \multirow[t]{2}{*}{ SNP } & \multirow[t]{2}{*}{ Group } & \multicolumn{2}{|c|}{ Allele } & \multicolumn{2}{|c|}{ Allele n (\%) } & \multirow[t]{2}{*}{ OR $(95 \% C I)$} & \multirow[t]{2}{*}{$P$} & \multicolumn{3}{|c|}{ Genotype n (\%) } & \multirow[t]{2}{*}{$P$} \\
\hline & & & 1 & 2 & 1 & 2 & & & 11 & 12 & 22 & \\
\hline \multirow[t]{2}{*}{ IL-21 } & rs2221903 & $\mathrm{HCC}$ & $\mathrm{A}$ & $\mathrm{G}$ & 227 (87.98) & $31(12.02)$ & \multirow{2}{*}{$0.43[0.13-1.45]$} & \multirow{2}{*}{0.17} & $102(79.07)$ & $23(17.83)$ & $4(3.01)$ & \multirow{2}{*}{0.20} \\
\hline & & Control & & & 619 (87.68) & $87(12.32)$ & & & $270(76.49)$ & $79(22.38)$ & $4(1.13)$ & \\
\hline \multirow[t]{2}{*}{ IL-21 } & rs4833837 & $\mathrm{HCC}$ & A & G & $233(90.31)$ & $25(9.69)$ & \multirow{2}{*}{$2.95[0.85-10.25]$} & \multirow{2}{*}{0.09} & $105(81.40)$ & $23(17.83)$ & $1(0.77)$ & \multirow{2}{*}{0.46} \\
\hline & & Control & & & 617 (87.39) & $89(12.61)$ & & & $270(76.49)$ & $77(21.81)$ & $6(1.70)$ & \\
\hline \multirow[t]{2}{*}{ IL-21R } & rs 2285452 & $\mathrm{HCC}$ & A & G & $29(11.24)$ & $229(88.76)$ & \multirow{2}{*}{$1.34[0.78-2.30]$} & \multirow{2}{*}{0.30} & $8(6.02)$ & $13(10.08)$ & $108(83.72)$ & \multirow{2}{*}{0.007} \\
\hline & & Control & & & $80(11.33)$ & $626(88.67)$ & & & $7(1.98)$ & $66(18.70)$ & $280(79.32)$ & \\
\hline \multirow[t]{2}{*}{ STAT3 } & rs 1053023 & $\mathrm{HCC}$ & A & G & $170(65.89)$ & $88(34.11)$ & \multirow{2}{*}{$0.74[0.47-1.17]$} & \multirow{2}{*}{0.20} & $55(42.64)$ & $60(46.51)$ & $14(10.85)$ & \multirow{2}{*}{0.78} \\
\hline & & Control & & & $482(68.27)$ & $224(31.73)$ & & & $162(45.89)$ & $158(44.76)$ & $33(9.35)$ & \\
\hline \multirow[t]{2}{*}{ JAK3 } & rs 3008 & $\mathrm{HCC}$ & $\mathrm{T}$ & $\mathrm{C}$ & $141(54.65)$ & $117(43.35)$ & \multirow{2}{*}{$1.14[0.74-1.75]$} & \multirow{2}{*}{0.55} & $24(18.60)$ & $69(53.49)$ & $36(27.91)$ & \multirow{2}{*}{0.31} \\
\hline & & Control & & & 395 (55.95) & $311(44.05)$ & & & $75(21.25)$ & $161(45.61)$ & $117(33.14)$ & \\
\hline
\end{tabular}

$\mathrm{CI}=$ confidence interval, $\mathrm{OR}=$ odds ratio, $\mathrm{SNP}=$ single nucleotide polymorphism.

Table 8: The correlation analysis between the genotype and the Serological marker mode of HBV patients

\begin{tabular}{|c|c|c|c|c|c|c|c|c|c|c|c|c|c|c|c|c|}
\hline & \multirow[t]{2}{*}{$\mathbf{n}(\%)$} & \multicolumn{3}{|c|}{ rs2221903 $(I L-21)$} & \multicolumn{3}{|c|}{ rs4833837 (IL-21) } & \multicolumn{3}{|c|}{ rs2285452 $(I L-21 R)$} & \multicolumn{3}{|c|}{ rs1053023 (STAT3) } & \multicolumn{3}{|c|}{ rs3008(JAK3) } \\
\hline & & $\mathbf{A A}$ & AG & GG & $\mathbf{A A}$ & AG & GG & $\mathbf{A A}$ & AG & GG & $\mathbf{A A}$ & AG & GG & TT & TC & $\mathrm{CC}$ \\
\hline \multicolumn{17}{|l|}{ Mode } \\
\hline 135 & $\begin{array}{c}115 \\
(44.75)\end{array}$ & $\begin{array}{c}88 \\
(76.52)\end{array}$ & $\begin{array}{c}26 \\
(22.61)\end{array}$ & $\begin{array}{c}1 \\
(0.87)\end{array}$ & $\begin{array}{c}87 \\
(75.65)\end{array}$ & $\begin{array}{c}26 \\
(22.61)\end{array}$ & $\begin{array}{c}2 \\
(1.74)\end{array}$ & $\begin{array}{c}3 \\
(2.61)\end{array}$ & $\begin{array}{c}14 \\
(12.17)\end{array}$ & $\begin{array}{c}98 \\
(85.22)\end{array}$ & $\begin{array}{c}51 \\
(44.35)\end{array}$ & $\begin{array}{c}58 \\
(50.43)\end{array}$ & $\begin{array}{c}6 \\
(5.22)\end{array}$ & $33(28.70)$ & $\begin{array}{c}62 \\
(53.91)\end{array}$ & $\begin{array}{c}20 \\
(17.39)\end{array}$ \\
\hline 13 & $\begin{array}{c}1 \\
(0.39)\end{array}$ & - & $\begin{array}{c}1 \\
(100.00)\end{array}$ & - & - & $\begin{array}{c}1 \\
(100.00)\end{array}$ & - & - & - & $\begin{array}{c}1 \\
(100.00)\end{array}$ & - & $\begin{array}{c}1 \\
(100.00)\end{array}$ & - & - & $\begin{array}{c}1 \\
(100.00)\end{array}$ & - \\
\hline 1345 & $\begin{array}{c}21 \\
(8.2)\end{array}$ & $\begin{array}{c}18 \\
(85.71)\end{array}$ & $\begin{array}{c}3 \\
(14.29)\end{array}$ & - & $\begin{array}{c}18 \\
(85.71)\end{array}$ & $\begin{array}{c}3 \\
(14.29)\end{array}$ & - & - & $\begin{array}{c}4 \\
(19.05)\end{array}$ & $\begin{array}{c}17 \\
(80.95)\end{array}$ & $\begin{array}{c}11 \\
(52.38)\end{array}$ & $\begin{array}{c}7 \\
(33.33)\end{array}$ & $\begin{array}{c}3 \\
(14.29)\end{array}$ & $\begin{array}{c}6 \\
(28.57)\end{array}$ & $\begin{array}{c}10 \\
(47.62)\end{array}$ & $\begin{array}{c}5 \\
(23.81)\end{array}$ \\
\hline 1235 & $\begin{array}{c}1 \\
(0.39)\end{array}$ & - & $\begin{array}{c}1 \\
(100.00)\end{array}$ & - & - & $\begin{array}{c}1 \\
(100.00)\end{array}$ & - & - & - & $\begin{array}{c}1 \\
(100.00)\end{array}$ & $\begin{array}{c}1 \\
(100.00)\end{array}$ & - & - & - & $\begin{array}{c}1 \\
(100.00)\end{array}$ & - \\
\hline 12345 & $\begin{array}{c}1 \\
(0.39)\end{array}$ & $\begin{array}{c}1 \\
(100.00)\end{array}$ & - & - & $\begin{array}{c}1 \\
(100.00)\end{array}$ & - & - & $\begin{array}{c}1 \\
(100.00)\end{array}$ & - & - & - & $\begin{array}{c}1 \\
(100.00)\end{array}$ & - & - & $\begin{array}{c}1 \\
(100.00)\end{array}$ & - \\
\hline 145 & $\begin{array}{c}96 \\
(37.35)\end{array}$ & $\begin{array}{c}79 \\
(82.29)\end{array}$ & $\begin{array}{c}15 \\
(15.63)\end{array}$ & $\begin{array}{c}2 \\
(2.08)\end{array}$ & $\begin{array}{c}77 \\
(80.21)\end{array}$ & $\begin{array}{c}15 \\
(15.63)\end{array}$ & $\begin{array}{c}4 \\
(4.16)\end{array}$ & $\begin{array}{c}1 \\
(1.04)\end{array}$ & $\begin{array}{c}15 \\
(15.63)\end{array}$ & $\begin{array}{c}80 \\
(83.33)\end{array}$ & $\begin{array}{c}43 \\
(44.79)\end{array}$ & $\begin{array}{c}43 \\
(44.79)\end{array}$ & $\begin{array}{c}10 \\
(10.42)\end{array}$ & $\begin{array}{c}34 \\
(35.42)\end{array}$ & $\begin{array}{c}47 \\
(48.96)\end{array}$ & $\begin{array}{c}15 \\
(15.62)\end{array}$ \\
\hline 1245 & $\begin{array}{c}4 \\
(1.56)\end{array}$ & $\begin{array}{c}4 \\
(100.00)\end{array}$ & - & - & $\begin{array}{c}4 \\
(100.00)\end{array}$ & - & - & $\begin{array}{c}1 \\
(25.00)\end{array}$ & - & $\begin{array}{c}3 \\
(75.00)\end{array}$ & $\begin{array}{c}2 \\
(50.00)\end{array}$ & $\begin{array}{c}2 \\
(50.00)\end{array}$ & - & $\begin{array}{c}2 \\
(50.00)\end{array}$ & $\begin{array}{c}2 \\
(50.00)\end{array}$ & - \\
\hline 15 & $\begin{array}{c}18 \\
(7.00)\end{array}$ & $\begin{array}{c}16 \\
(88.89)\end{array}$ & $\begin{array}{c}2 \\
(11.11)\end{array}$ & - & $\begin{array}{c}16 \\
(88.89)\end{array}$ & $\begin{array}{c}2 \\
(11.11)\end{array}$ & - & - & $\begin{array}{c}3 \\
(16.67)\end{array}$ & $\begin{array}{c}15 \\
(83.33)\end{array}$ & $\begin{array}{c}10 \\
(55.56)\end{array}$ & $\begin{array}{c}6 \\
(33.33)\end{array}$ & $\begin{array}{c}2 \\
(11.11)\end{array}$ & $\begin{array}{c}8 \\
(44.44)\end{array}$ & $\begin{array}{c}5 \\
(27.78)\end{array}$ & $\begin{array}{c}5 \\
(27.78)\end{array}$ \\
\hline$P$ & & & 0.46 & & & 0.36 & & & 0.00 & & & 0.81 & & & 0.79 & \\
\hline
\end{tabular}

1: HBsAg; 2: anti-HBs; 3: HBeAg; 4: anti-HBe; 5: anti-HBc. 135: $\mathrm{HBsAg}(+), \mathrm{HBeAg}(+)$, anti-HBc(+); 13: $\operatorname{HBsAg}(+), \operatorname{HBeAg}(+)$; $1345: \mathrm{HBsAg}(+)$, $\mathrm{HBeAg}(+)$, anti-HBe $(+)$, anti-HBc(+); 1235: $\mathrm{HBsAg}(+)$, anti-HBs $(+), \mathrm{HBeAg}(+)$, anti-HBc $(+)$; 12345: $\mathrm{HBsAg}(+)$, anti-HBs $(+), \mathrm{HBeAg}(+)$, anti$\mathrm{HBe}(+)$, anti-HBc $(+)$; 145: $\mathrm{HBsAg}(+)$, anti-HBe $(+)$, anti-HBc $(+)$; 1245: $\mathrm{HBsAg}(+)$, anti-HBs $(+)$, anti-HBe $(+)$, anti-HBc $(+)$; 15: $\mathrm{HBsAg}(+)$, anti$\operatorname{HBc}(+)$.

antibody-dependent cytotoxicity of NK cells. IL-21 in combination with soluble programmed death receptor-1 (PD-1) stimulated different periods of B lymphocyte,
T lymphocyte and NK cell proliferation by IL-2, IFN $\gamma$, whereas, down-regulation of IL-10 significantly inhibited tumor growth [31, 41]. Furthermore, HBV infection 
Table 9: The correlation analysis between the allele frequency and the Serological marker mode of HBV

\begin{tabular}{|c|c|c|c|c|c|c|c|c|c|c|}
\hline \multirow[t]{2}{*}{ SNPs } & \multirow[t]{2}{*}{ Allele } & \multicolumn{8}{|c|}{ Serological marker mode } & \multirow[t]{2}{*}{$\mathbf{P}$} \\
\hline & & $135(n=230)$ & $13(n=2)$ & $1345(n=42)$ & $1235(n=2)$ & $12345(n=2)$ & $145(n=192)$ & $1245(n=8)$ & $15(n=36)$ & \\
\hline \multirow{2}{*}{$\begin{array}{l}\text { rs2221903 } \\
(I L-21)\end{array}$} & $\mathbf{A}$ & $202(87.83)$ & $1(50.00)$ & $39(92.86)$ & $1(50.00)$ & $2(100.00)$ & $173(90.10)$ & $8(100.00)$ & $34(94.45)$ & \multirow[t]{2}{*}{0.19} \\
\hline & G & $28(12.17)$ & $1(50.00)$ & $3(7.14)$ & $1(50.00)$ & - & $19(9.90)$ & - & $2(5.56)$ & \\
\hline \multirow{2}{*}{$\begin{array}{l}\text { rs4833837 } \\
(I L-21)\end{array}$} & $\mathbf{A}$ & $200(86.96)$ & $1(50.00)$ & 39 (92.86) & $1(50.00)$ & $2(100.00)$ & $169(88.02)$ & $8(100.00)$ & $34(94.45)$ & \multirow[t]{2}{*}{0.21} \\
\hline & G & $30(13.04)$ & $1(50.00)$ & $3(7.14)$ & $1(50.00)$ & - & 23 (11.98) & - & $2(5.56)$ & \\
\hline \multirow{2}{*}{$\begin{array}{l}\text { rs2285452 } \\
\text { (IL-21R) }\end{array}$} & $\mathbf{A}$ & $20(8.70)$ & - & $4(9.52)$ & - & $2(100.00)$ & $17(8.85)$ & $2(25.00)$ & $3(8.33)$ & \multirow[t]{2}{*}{0.00} \\
\hline & G & $210(91.30)$ & $2(100.00)$ & $38(90.48)$ & $2(100.00)$ & - & $175(91.15)$ & $6(75.00)$ & $33(91.67)$ & \\
\hline \multirow{2}{*}{$\begin{array}{l}\text { rs1053023 } \\
\text { (STAT3) }\end{array}$} & $\mathbf{A}$ & $160(69.57)$ & $1(50.00)$ & $29(69.05)$ & $2(100.00)$ & $1(50.00)$ & 129 (67.19) & $6(75.00)$ & $26(72.22)$ & \multirow[t]{2}{*}{0.95} \\
\hline & G & $70(30.43)$ & $1(50.00)$ & $13(30.95)$ & - & $1(50.00)$ & $63(32.81)$ & $2(25.00)$ & $10(27.78)$ & \\
\hline \multirow{2}{*}{$\begin{array}{l}\text { rs3008 } \\
\text { (JAK3) }\end{array}$} & $\mathbf{T}$ & $128(55.65)$ & $1(50.00)$ & $22(52.38)$ & $1(50.00)$ & $1(50.00)$ & $115(59.90)$ & $6(75.00)$ & $21(58.33)$ & \multirow[t]{2}{*}{0.94} \\
\hline & C & $102(44.35)$ & $1(50.00)$ & $20(47.62)$ & $1(50.00)$ & $1(50.00)$ & 77 (40.10) & $2(25.00)$ & 15 (41.67) & \\
\hline
\end{tabular}

1: HBsAg; 2: anti-HBs; 3: HBeAg; 4: anti-HBe; 5: anti-HBc. 135: $\mathrm{HBsAg}(+), \mathrm{HBeAg}(+)$, anti-HBc(+); 13: $\mathrm{HBsAg}(+), \mathrm{HBeAg}(+) ; 1345$ : $\mathrm{HBsAg}(+), \mathrm{HBeAg}(+)$, anti-HBe $(+)$, anti-HBc $(+)$; 1235: $\mathrm{HBsAg}(+)$, anti-HBs(+), $\mathrm{HBeAg}(+)$, anti-HBc $(+)$; $12345: \mathrm{HBsAg}(+)$, anti$\mathrm{HBs}(+), \operatorname{HBeAg}(+)$, anti-HBe$(+)$, anti-HBc $(+)$; 145: $\operatorname{HBsAg}(+)$, anti-HBe(+), anti-HBc $(+)$; 1245: $\operatorname{HBsAg}(+)$, anti-HBs $(+)$, anti-HBe $(+)$, anti-HBc(+); 15: $\mathrm{HBsAg}(+)$, anti-HBc(+).

Table 10: Primer sequences of the target SNPs

\begin{tabular}{|c|c|c|c|c|}
\hline Gene & SNPs & & Primer & Length \\
\hline \multirow[t]{4}{*}{$I L-21$} & rs2221903 & $\mathrm{A} / \mathrm{G}$ & F:5'-AGACACAGCTCTGCTGCTTG-3' & 116 \\
\hline & & & R:5'-CACTGACGCCCATATTGATG-3' & \\
\hline & rs4833837 & $\mathrm{A} / \mathrm{G}$ & F:5'-TTTGTGGAAGGTGGTTTCCT-3' & 120 \\
\hline & & & R:5'-TGAGTGGTCAGCTTTTTCCTG-3' & \\
\hline \multirow[t]{2}{*}{$I L-21 R$} & rs2285452 & $\mathrm{G} / \mathrm{A}$ & F:5'-CTGGGATAATGCCCATGGTA-3’' & 126 \\
\hline & & & R:5'-ACGGCTGTTGTCATCTGTTG-3' & \\
\hline \multirow[t]{2}{*}{$J A K 3$} & rs3008 & $\mathrm{T} / \mathrm{C}$ & F:5'-GGCCTTATGAGGGTCCTCTACT-3' & 122 \\
\hline & & & R:5'-ATGCCCATCTGTCTTGAACC-3' & \\
\hline \multirow[t]{2}{*}{ STAT3 } & rs1053023 & $\mathrm{A} / \mathrm{G}$ & F:5'-AGGGCTTCTCTGGAGCAGAT-3' & 135 \\
\hline & & & R:5'-GCCTGAGGACCCTGTTCTTT-3' & \\
\hline
\end{tabular}

promotes HCC, whereas, activated CD4+ T lymphocytes and NK cells that produce IL-21 play a critical role in antitumor immunity [39]. Moreover, HBV infection suppresses NK cell proliferation, differentiation or activation [38]. Although we did not find a difference, previous studies have shown that IL-21 and IL-21R play an important role in promoting liver fibrosis. They are associated with a significant increase in $\mathrm{HBV}$ in patients with liver cirrhosis. Excessive IL-21 is produced by the peripheral Thl7 cells and liver cells, which further results in induced activation of hepatic stellate cells, which contributes to the severity of the disease and high expression of IL-17 and IL -21 by the Thl7 cells [42].
IL-21 activates the JAK-STAT, PI 3-kinase (PI3K), and MAPK signaling pathways [43]. The activation of the JAK-STAT signaling pathway by IL-21 has been extensively studied in this [44]. JAK3 and STAT3 are the key proteins in the JAK-STAT signaling pathway. Polymorphisms in the STAT3 gene are associated with a variety of tumors. The STAT3 rs1053023 SNP in the 3'UTR reduces the risk of B-cell non-Hodgkin's lymphoma as well as other lymphoma subtypes such as Diffuse large B-cell lymphoma (DLBCL), Follicular lymphoma (FL) and Chronic lymphocytic leukaemia (CLL) [45, 46]. However, the relationship between STAT3 rs1053023 SNP and $\mathrm{HBV}$ is unclear. In our study, there was no association 
between HBV pathogenesis and STAT3 rs1053023 and $J A K 3$ rs3008 SNPs. However, STAT3 promotes cell cycle progression and cell proliferation of hepatocytes in response to liver regeneration $[47,48]$. Hence, further studies are needed to explore the role of SNPs in the JAKSTAT pathway in susceptibility to infectious diseases.

The serological markers (HBsAg, anti-HBs Ab, $\mathrm{HBeAg}$, anti-HBe $\mathrm{Ab}$ and anti-HBc $\mathrm{Ab}$ ) are closely associated with the diagnosis of HBV infection [49]. In general, they are used to determine if a suspected individual is suffering from $\mathrm{HBV}$ infection and estimate the replication status of HBV. The serological markers showed variability probably due to individual variations. In our study, there was no association between the genotype and allele frequency of the 5 polymorphisms and the 8 serological marker modes. Although there was significant correlation between the serological marker modes and the distribution of the $I L-21 R$ rs2285452 genotypes and alleles $(\mathrm{P}=0.00, \mathrm{P}=0.00$, respectively), the findings need to be confirmed by larger sample sizes because insufficient sample size may have caused a bias. Moreover, IL-21 serum levels modulate HBsAg seroconversion during treatment [45].

The main limitation of our study is the limited sample size. Hence, the functional consequences of the SNPs in the IL-21-JAK/STAT signaling pathway in HBVrelated pathogenesis needs to be confirmed by large-scale studies in the future.

In summary, our study demonstrates that the $I L-21 R$ rs2285452 AA genotype is a risk factor for HBV infections and HBV-related HCC. Our study suggests that SNPs in the IL21-JAK-STAT signaling pathway modulate host immune responses to HBV infection and influence HBVrelated disease outcomes.

\section{MATERIALS AND METHODS}

\section{Ethics statement}

This study was approved by the Ethics Committee of West China Hospital, Sichuan University and conducted according to the World Medical Association Declaration of Helsinki guidelines. Signed informed consent forms were obtained from all the study subjects.

\section{Study subjects}

We recruited $546 \mathrm{HBV}$ patients that were diagnosed at the West China Hospital of Sichuan University between May 2014 and December 2015. These patients were further divided into three subgroups based on the disease progression, namely, chronic hepatitis B (CHB; 302 cases), cirrhosis (115 cases) and hepatocellular carcinoma (HCC; 129 cases). Two physicians independently diagnosed and evaluated each patient according to the following criteria: (1) CHB subgroup: patients with an
HBV infection history based on HbsAg positivity for more than six months; patients were all HBsAg positive and in some cases HBV DNA positive; high serum ALT levels or histological examination showed inflammatory liver injury; (2) Cirrhosis subgroup: histological examination showed diffuse fibroplasias and pseudolobules in addition to CHB-related pathology; (3) HCC subgroup: HCC was diagnosed and staged considering the HBV infection history, clinical symptoms, imaging data, and AFP test results.

We excluded individuals with a history of other infectious diseases such as HIV and syphilis and other complex health problems, such as cardiomyopathy, hypertension or diabetes. We also enrolled 353 healthy subjects based on physical examination from the general population. Based on the HBV serological marker testing, the controls were divided into negative (253 cases) and anti-HBs positive (100 cases) subgroups.

\section{Selection of SNPs}

We searched the dbSNP (http://www.ncbi.nlm.nih. gov/projects/SNP/), miRBase registry (http://microrna. sanger.ac.uk) to identify SNPS in the $I L-21, I L-21 R, J A K 3$ and STAT3 genes with a minor allele frequency (MAF) $\geq$ 0.05 . We identified 5 potential functional polymorphisms namely rs2221903 and rs4833837 in $I L-21$, rs2285452 in $I L-21 R$, rs 3008 in JAK3 and rs1053023 in STAT3 based on the following criteria: (1) reported MAF was $\geq 0.10$ for the SNPs in the Chinese Han population; (2) SNPs were located in potential functional regions such as exons, UTRs and promoters (within $2 \mathrm{~kb}$ of the genes); (3) sequencing primers were available; and (4) SNPs were reported in previous studies.

\section{Genomic DNA extraction}

We collected 5-10 $\mathrm{ml}$ peripheral blood sample with disposable syringes under aseptic conditions from each study subject. Then, genomic DNA was extracted from $200 \mu$ of blood using the QIAamp ${ }^{\circledR}$ DNA Blood mini kit (Qiagen, Germany) according to the manufacturer's instructions. The DNA was quantified in each sample and then diluted to $10 \mathrm{ng} / \mu \mathrm{L}$ with $\mathrm{AE}$ buffer(10 mM Tris-Cl 0.5 mM EDTA; pH 9.0).

\section{Genotyping by HRM analysis}

The PCR primers used to detect the five SNPs by the high resolution melting (HRM) method are shown in Table 10. The primers were designed using Primer premier 3.0 (http://bioinfo.ut.ee/primer3-0.4.0/) for the target gene sequences obtained from NCBI website (http://blast.ncbi. nlm.nih.gov/).

PCR was performed in the LightCycler 480 RealTime PCR System (Roche Diagnostics). The total PCR 
reaction mixture $(10 \mu \mathrm{L})$ contained $5 \mu \mathrm{L}$ of Roche PCR mix (DNA Polymerase, dNTP, buffer and fluorescent dye), $2.5 \mu \mathrm{L}$ of $\mathrm{MgCl} 2$ (Roche), $0.2 \mu \mathrm{L}$ each of forward and reverse primers, $2.4 \mu \mathrm{L}$ of double-distilled water and 1 $\mu \mathrm{L}$ of purified genomic DNA. The PCR protocol included hot start at $95^{\circ} \mathrm{C}$ for $15 \mathrm{~min}$ followed by 55 cycles of denaturation at $95^{\circ} \mathrm{C}$ for $15 \mathrm{~s}$, annealing at $63^{\circ} \mathrm{C}$ for $10 \mathrm{~s}$, and extension at $72^{\circ} \mathrm{C}$ for $10 \mathrm{~s}$. Then, HRM analysis was performed by denaturing at $95^{\circ} \mathrm{C}$ for $30 \mathrm{~s}$, cooling to $65^{\circ} \mathrm{C}$ and then gradually increasing the temperature from $65^{\circ} \mathrm{C}$ to $95^{\circ} \mathrm{C}$ at a rate of $1^{\circ} \mathrm{C} / \mathrm{s}$ in $30 \mathrm{~s}$. Finally, the reaction was cooled to $40^{\circ} \mathrm{C}$ for $30 \mathrm{~s}$. Data were collected and analyzed by the LightCycler® 480 Gene Scanning software v1.2 (Roche Diagnostics, Germany). First, normalization was performed by selecting linear regions before $(100 \%$ fluorescence) and after ( $0 \%$ fluorescence) the melting transition. Then, temperature shift was carried out by selecting a threshold using the LightCycler ${ }^{\circledR} 480$ Gene Scanning software v1.2 (Roche Diagnostics, Germany). Finally, HRM curve's calculations and automatic groupings were performed in each sample. Samples with delayed PCR amplification or with less than $60 \%$ fluorescence than the average were excluded. The samples were divided into various subsets based on the differences in the melting curve clusters, and then genotyping was determined relative to the reference samples of known genotypes. To improve the reliability of genotyping, three control samples of each SNP were run in all experiments [50]. Random samples were verified by sequencing.

\section{DNA sequencing}

The genotypes of some samples were previously confirmed by sequencing the control samples of the five SNPs. The PCR products were purified using 1 unit of Shrimp Alkaline Phosphatase. Then, the PCR samples were treated with Shrimp Alkaline Phosphatase (SAP) and sequenced using the same forward primers for the 5 SNPs that were used for the PCR with the BigDye Terminator v3.1 Cycle Sequencing Kit and the sequence was determined using the ABI 3130 genetic analyzer (Applied Biosystems).

\section{Detection of the HBV serological markers}

We collected $3 \mathrm{~mL}$ peripheral vein blood samples from patients into vacuum tubes containing heparin. After separating out the blood cells, we determined the HBV serological markers in the plasma: 1:HBsAg; 2: anti-HBs; 3: $\mathrm{HBeAg}$; 4: anti-HBe; 5: anti-HBc by using the Modular Analytics E170 (Roche Diagnostics), and there are eight different modes. The most popular mode was " 135 " (HBsAg+, $\mathrm{HBeAg}+$, anti-HBc + ) which prompted the virus replication stage with serious infectivity, followed by the mode of "145" (HBsAg+, anti-HBe+, anti-HBc +), in addition to " 135 " and " 145 ", there were including six rare modes ("13", "1345", “1235", “1245", "15" and "12345”). "13" (HBsAg+, HBeAg+) usually appeared in chronic carriers with strong infection; the contagious capability of subjects with "15" (HBsAg+, anti-HBc +) was relatively weak; "1345" (HBsAg+, $\mathrm{HBeAg}+$, anti-HBe+, anti-HBc + ) prompted the chronic infection; "1235" (HBsAg+, anti$\mathrm{HBs}+, \mathrm{HBeAg}+$, anti-HBc + ) and "1245" (HBsAg+, anti$\mathrm{HBs}^{+}$, anti-HBe+, anti-HBc + ) prompted the subclinical or atypical infection; "12345" (HBsAg+, anti-HBs+, $\mathrm{HBeAg}+$, anti-HBe+, anti-HBc + ) may prompt that the anti-HBs generated by the bodies have mutated. [49].

\section{Statistical analysis}

The data regarding age and gender of the different patient subgroups and control subjects was analyzed by the $t$-test and Pearson $\chi 2$ test. The deviation of HardyWeinberg equilibrium (HWE) for each group was assessed using the online SHEsis software (http://analysis2.bio-x. $\mathrm{cn} / \mathrm{SHEsisMain.htm).} \mathrm{The} \mathrm{assessment} \mathrm{of} \mathrm{the} \mathrm{genotype} \mathrm{and}$ the allele frequencies as well as their association with the subgroup pathology was determined as follows: (a) Binary Logistic Regression model was used to compare HBVinfected patients as well as cirrhosis and HCC subgroup patients with their corresponding controls; (b) Pearson $\chi^{2}$ analysis was used to compare HBV-infected patients and the CHB subgroup with their controls. The effect of SNPs was tested for odds ratio (OR), 95\% confidence interval (CI). All statistical analyses were performed by the SPSS 17.0 software. $\mathrm{P}<0.05$ was considered statistically significant.

\section{Abbreviations}

HBV: Hepatitis B virus; IL-21: Interleukin-21; JAK-STAT: Janus tyrosine kinase-signal transducer and activator of transcription; HRM: high resolution melting; CHB: chronic hepatitis B ; HCC: hepatocellular carcinoma; SNP: single nucleotide polymorphisms; NK: natural killer cells; CD: cluster of differentiation; HBsAg: hepatitis B surface-antigen; anti-HBs Ab: anti-hepatitis B surface-antigen antibody; $\mathrm{HBeAg}$ : hepatitis B e-antigen; anti-HBe Ab: anti-hepatitis B e-antigen antibody; anti$\mathrm{HBc} \mathrm{Ab}$ : anti-hepatitis b core-antigen antibody.

\section{Author contributions}

TL, MZ, JS, and SL performed the experiments and wrote the manuscript; JZ, ZZ and XH modified the manuscript; WP, QW and HB analyzed the data and prepared tables and figures for the manuscript; YL participated in part of the experiments; JL and BY designed the study; all the authors reviewed the manuscript. 


\section{ACKNOWLEDGMENTS AND FUNDING}

The authors thank all the study subjects for participation in this study. This work was supported by grants from the National Natural Science Foundation of China [Grant Nos.: 81472026, 81672095, 81672096] and the Projects in the Science and Technology Department of Sichuan Province pillar program [Grant No.: 2014SZ0208].

\section{CONFLICTS OF INTEREST}

The authors declare that there are no conflicts of interest.

\section{REFERENCES}

1. WHO, Global hepatitis report, 2017; http://www.who.int/ hepatitis/publications/global-hepatitis-report2017/en/, (Date of access: 25/04/2017) (2017).

2. Abubakar II, Tillmann T, Banerjee A. Global, regional, and national age-sex specific all-cause and cause-specific mortality for 240 causes of death, 1990-2013: a systematic analysis for the global burden of disease study 2013. Lancet. 2015; 385:117-171. http://dx.doi.org/10.1016/ S0140-6736(14)61682-2.

3. World Health Organization. Regional Office for the Western Pacific. China-WHO country cooperation strategy 20162020.WPRO/2016/DPM/003.2016:4; http://apps.who.int/ iris/bitstream/10665/206615/1/WPRO_2016_DPM_003 chi.pdf?ua $=1$.

4. Lebre MC, Vieira PL, Tang MW, Aarrass S, Helder B, Newsom-Davis T, Tak PP, Screaton GR. Synovial IL-21/ TNF-producing CD4+ T cells induce joint destruction in rheumatoid arthritis by inducing matrix metalloproteinase production by fibroblast-like synoviocytes. J Leuk Biol. 2017; 101:775-783. http://dx.doi.org/10.1189/ jlb.5A0516-217RR.

5. Spolski R, Leonard WJ. Interleukin-21: a double-edged sword with therapeutic potential. Nat Rev Drug Discov. 2014;13:379-395. http://dx.doi.org/10.1038/nrd4296.

6. Parrishnovak J, Dillon SR, Nelson A, Hammond A, Sprecher C, Gross JA, Johnston J, Madden K, Xu W, West J. Interleukin 21 and its receptor are involved in NK cell expansion and regulation of lymphocyte function. Nature. 2000; 408:57-63. http://dx.doi.org/10.1038/35040504.

7. Moens L, Tangye SG. Cytokine-mediated regulation of plasma cell generation: IL-21 takes center stage. Front Immunol. 2014; 5:65. http://dx.doi.org/10.3389/ fimmu.2014.00065.

8. Bhatt S, Sarosiek KA, Lossos IS. Interleukin 21-its potential role in the therapy of B-cell lymphomas. Leuk Lymph. 2017; 58:17-29. http://dx.doi.org/10.1080/104281 94.2016.1201568.
9. Netchiporouk E, Litvinov IV, Moreau L, Gilbert M, Sasseville D, Duvic M. Deregulation in STAT signaling is important for cutaneous T-cell lymphoma (CTCL) pathogenesis and cancer progression. Cell Cycle. 2014; 13:3331-3335. http://dx.doi.org/10.4161/15384101.2014. 965061.

10. Wang YC, Cui XB, Chuang YH, Chen SY. Janus kinase 3, a novel regulator for smooth muscle proliferation and vascular remodeling. Arterioscler Thromb Vasc Biol. 2017; 37:13521360. http://dx.doi.org/10.1161/ATVBAHA.116.308895.

11. Yuan X, Dou Y, Wu X, Wei Z, Dai Y. Tetrandrine, an agonist of aryl hydrocarbon receptor, reciprocally modulates the activities of STAT3 and STAT5 to suppress Th17 cell differentiation. J Cell Mol Med. 2017; 21:2172-2183. http://dx.doi.org/10.1111/jcmm.13141.

12. Sim SH, Kim S, Kim TM, Jeon YK, Nam SJ, Ahn YO, Keam B, Park HH, Kim DW, Kim CW, Heo DS. Novel JAK3-activating mutations in extranodal NK/T-Cell lymphoma, nasal type. Am J Pathol. 2017; 187:980-986. http://dx.doi.org/10.1016/j.ajpath.

13. Zhang QX, Li SL, Yao YQ, Li TJ. Association between interleukin-21 gene polymorphisms (rs12508721) and HBV-related hepatocellular carcinoma. Int J Immunogenet. 2016; 43:151-158. http://dx.doi.org/10.1111/iji.12263.

14. Li Y, Tang L, Hou J. Role of interleukin-21 in HBV infection: friend or foe? Cell Mol Immunol. 2015; 12:303308. http://dx.doi.org/10.1038/cmi.2014.109.

15. Ding R, Ma SW. Research advances in the role of interleukin-21 in chronic hepatitis B virus infection. Chin J Hepatol. 2016; 24:469-473. http://dx.doi.org/10.3760/ cma.j.issn.1007-3418.

16. Publicover J, Goodsell A, Nishimura S, Vilarinho S, Wang ZE, Avanesyan L, Spolski R, Leonard WJ, Cooper S, Baron JL. IL-21 is pivotal in determining age-dependent effectiveness of immune responses in a mouse model of human hepatitis B. J Clin Invest. 2011; 121:1154-1162. http://dx.doi.org/10.1172/JCI44198.

17. Feng G, Zhang JY, Zeng QL, Yu X, Zhang Z, Lv S, Xu $\mathrm{X}$, Wang FS. Interleukin-21 mediates hepatitis B virusassociated liver cirrhosis by activating hepatic stellate cells. Hepatol Res. 2014; 44:E198-E205. http://dx.doi. org/10.1111/hepr.12215.

18. Churin Y, Roderfeld M, Stiefel J, Wurger T, Schroder D, Matono T, Mollenkopf HJ, Montalbano R, Pompaiah M, Reifenberg K, Zahner D, Ocker M, Gerlich W, et al. Pathological impact of hepatitis B virus surface proteins on the liver is associated with the host genetic background. PLoS One. 2014; 9:e90608. http://dx.doi.org/10.1371/ journal.pone.0090608.

19. Dandri M, Locarnini S. New insight in the pathobiology of hepatitis B virus infection. Gut. 2012; 61:i6-17. http:// dx.doi.org/10.1136/gutjnl-2012-302056.

20. Ding L, Wang S, Chen GM, Leng RX, Pan HF, Ye DQ. A single nucleotide polymorphism of IL-21 gene is 
associated with systemic lupus erythematosus in a Chinese population. Inflammation. 2012; 35:1781-1785. http:// dx.doi.org/10.1007/s10753-012-9497-7.

21. Zeng H, Yan H, Zhang Z, Fang W, Ding R, Huang L, Chen M, Zhang J. Association between IL-21 gene rs907715 polymorphisms and graves' disease in a southern Chinese population. Exp Ther Med. 2014; 8:213-218. http://dx.doi. org/10.3892/etm.2014.1707.

22. Li G, Xu R, Cao Y, Xie X, Zheng Z. Interleukin-21 polymorphism affects gene expression and is associated with risk of ischemic stroke. Inflammation. 2014; 37:2030 2039. http://dx.doi.org/10.1007/s10753-014-9935-9.

23. Yao JY, Chao K, Li MR, Wu YQ, Zhong BH. Interleukin-21 gene polymorphisms and chronic hepatitis B infection in a Chinese population. World J Gastroenterol. 2015; $21: 4232$ 4239. http://dx.doi.org/10.3748/wjg.v21.i14.4232.

24. You Y, Deng J, Zheng J, Hu M, Li N, Wu H, Li W, Lu J, Zhou Y. IL-21 gene polymorphism is associated with the prognosis of breast cancer in Chinese populations. Breast Cancer Res Treat. 2013; 137:893-901. http://dx.doi. org/10.1007/s10549-012-2401-1.

25. Xiao M, Hu S, Tang J, Zhang L, Jiang H. Interleukin (IL)21 promoter polymorphism increases the risk of thyroid cancer in Chinese population. Gene. 2014; 537:15-19. http://dx.doi.org/10.1016/j.gene.2013.12.050.

26. Sperati CJ, Parekh RS, Berthier-Schaad Y, Jaar BG, Plantinga L, Fink N, Powe NR, Smith MW, Coresh J, Kao WH. Association of single-nucleotide polymorphisms in JAK3, STAT4, and STAT6 with new cardiovascular events in incident dialysis patients. Am J Kidney Dis. 2009; 53:845-855. http://dx.doi.org/10.1053/j.ajkd.2008.12.025.

27. Vaclavicek A, Bermejo JL, Schmutzler RK, Sutter C, Wappenschmidt B, Meindl A, Kiechle M, Arnold N, Weber $\mathrm{BH}$, Niederacher D, Burwinkel B, Bartram CR, Hemminki $\mathrm{K}$, et al. Polymorphisms in the Janus kinase 2 (JAK)/signal transducer and activator of transcription (STAT) genes: putative association of the STAT gene region with familial breast cancer. Endocr Relat Cancer. 2007; 14:267-277. http://dx.doi.org/10.1677/ERC-06-0077.

28. Yamamoto K, Ioroi T, Kanaya K, Shinomiya K, Komoto S, Hirata S, Harada K, Watanabe A, Suno M, Nishioka T, Kume M, Makimoto H, Nakagawa T, et al. STAT3 polymorphism rs4796793 may be a predictive factor of tumor response to multiple tyrosine kinase inhibitors in metastatic renal cell carcinoma in Japanese population. Med Oncol. 2016;33:1-7. http://dx.doi.org/10.1007/ s12032-016-0733-0.

29. Kreil S, Waghorn K, Ernst T, Chase A, White H, Hehlmann R, Reiter A, Hochhaus A, Cross NC. A polymorphism associated with STAT3 expression and response of chronic myeloid leukemia to interferon alpha. Haematologica. 2010; 95:148-152. http://dx.doi.org/10.3324/ haematol.2009.011510.

30. Wang K, Zhou B, Zhang J, Xin Y, Lai T, Wang Y, Hou Q, Song Y, Chen Y, Quan Y, Xi M, Zhang L. Association of signal transducer and activator of transcription 3 gene polymorphisms with cervical cancer in Chinese women. DNA Cell Biol. 2011; 30:931-936. http://dx.doi. org/10.1089/dna.2010.1179.

31. Spolski R, Wang L, Wan CK, Bonville CA, Domachowske JB, Kim HP, Yu Z, Leonard WJ. IL-21 promotes the pathologic immune response to pneumovirus infection. J Immunol. 2012; 188:1924-1932. http://dx.doi.org/10.4049/ jimmunol.1100767.

32. Parmigiani A, Pallin MF, Schmidtmayerova H, Lichtenheld MG, Pahwa S. Interleukin-21 and cellular activation concurrently induce potent cytotoxic function and promote antiviral activity in human CD8 T cells. Hum Immunol. 2011; 72:115-123. http://dx.doi.org/10.1016/j. humimm.2010.10.015.

33. Yi JS, Du M, Zajac AJ. A vital role for interleukin-21 in the control of a chronic viral infection. Science. 2009; 324:1572-1576. http://dx.doi.org/10.1126/science.1175194.

34. Frohlich A, Kisielow J, Schmitz I, Freigang S, Shamshiev AT, Weber J, Marsland BJ, Oxenius A, Kopf M. IL-21R on $\mathrm{T}$ cells is critical for sustained functionality and control of chronic viral infection. Science. 2009; 324:1576-1580. http://dx.doi.org/10.1126/science.1172815.

35. Qi JH, Qi J, Xiang LN, Nie G. Association between IL-21 polymorphism and systemic lupus erythematosus: a metaanalysis. Genet Mol Res. 2015; 14:9595-9603. http:// dx.doi.org/10.4238/2015.August.14.22.

36. Sawalha AH, Kaufman KM, Kelly JA, Adler AJ, Aberle T, Kilpatrick J, Wakeland EK, Li QZ, Wandstrat AE, Karp DR, James JA, Merrill JT, Lipsky P, et al. Genetic association of interleukin-21 polymorphisms with systemic lupus erythematosus. Ann Rheumat Dis. 2008; 67:458-461. http:// dx.doi.org/10.1136/ard.2007.075424.

37. Ma SW, Huang X, Li YY, Tang LB, Sun XF, Jiang XT, Zhang YX, Sun J, Liu ZH, Abbott WG, Dong YH, Naoumov NV, Hou JL. High serum IL-21 levels after 12 weeks of antiviral therapy predict $\mathrm{HBeAg}$ seroconversion in chronic hepatitis B. J Hepatol. 2012; 56:775-781. http:// dx.doi.org/10.1016/j.jhep.2011.10.020.

38. Li N, Zhu Q, Li Z, Han Q, Chen J, Lv Y, Wang Y, Zeng X, Chen Y, Yang C, Liu Z. IL21 and IL21R polymorphisms and their interactive effects on serum IL-21 and IgE levels in patients with chronic hepatitis B virus infection. Hum Immunol. 2013; 74:567-573. http://dx.doi.org/10.1016/j. humimm.2013.01.005.

39. Ettinger R, Kuchen S, Lipsky PE. The role of IL-21 in regulating B-cell function in health and disease. Immunol Rev. 2008; 223:60-86. http://dx.doi. org/10.1111/j.1600-065X.2008.00631.x.

40. Zhang J, Xiao WX, Zhu YF, Muhali FS, Xiao L, Jiang WJ, Shi XH, Zhou LH, Zhang JA. Polymorphisms of interleukin-21 and interleukin-21-receptor genes confer risk for autoimmune thyroid diseases. BMC Endocr Disord. 2013; 13:26. http://dx.doi. org/10.1186/1472-6823-13-26. 
41. Pan XC, Li L, Mao JJ, Yao W, Zheng JN, Liu M, Fu JJ. Synergistic effects of soluble PD-1 and IL-21 on antitumor immunity against H22 murine hepatocellular carcinoma. Oncol Lett. 2013; 5:90-96. http://dx.doi.org/10.3892/ ol.2012.966.

42. Liu B, Gao W, Zhang L, Wang J, Chen M, Peng M, Ren H, $\mathrm{Hu}$ P. Th17/Treg imbalance and increased interleukin-21 are associated with liver injury in patients with chronic severe hepatitis B. Int Immunopharmacol. 2017; 46:48-55. http:// dx.doi.org/10.1016/j.intimp.2017.02.019.

43. Leonard WJ, Zeng R, Spolski R. Interleukin 21: a cytokine/cytokine receptor system that has come of age. J Leuk Biol. 2008; 84:348-356. http://dx.doi.org/10.1189/ jlb.0308149.

44. Wan CK, Andraski AB, Spolski R, Li P, Kazemian M, Oh J, Samsel L, Swanson PA 2nd, McGavern DB, Sampaio EP, Freeman AF, Milner JD, Holland SM, et al. Opposing roles of STAT1 and STAT3 in IL-21 function in CD4+ T cells. Proc Natl Acad Sci U S A. 2015; 112:9394-9399. http:// dx.doi.org/10.1073/pnas.1511711112.

45. Ito N, Eto M, Nakamura E, Takahashi A, Tsukamoto T, Toma H, Nakazawa H, Hirao Y, Uemura H, Kagawa $\mathrm{S}$, Kanayama H, Nose Y, Kinukawa N, et al. STAT3 polymorphism predicts interferon-alfa response in patients with metastatic renal cell carcinoma. J Clin Oncol. 2007; 25:2785-2791. http://dx.doi.org/10.1200/ JCO.2006.09.8897.
46. Butterbach K, Beckmann L, de Sanjose S, Benavente Y, Becker N, Foretova L, Maynadie M, Cocco P, Staines A, Boffetta P, Brennan P, Nieters A. Association of JAK-STAT pathway related genes with lymphoma risk: results of a European case-control study (EpiLymph). Br J Haematol. 2011; 153:318-333. http://dx.doi. org/10.1111/j.1365-2141.2011.08632.x.

47. Li W, Liang X, Kellendonk C, Poli V, Taub R. STAT3 contributes to the mitogenic response of hepatocytes during liver regeneration. J Biol Chem. 2002; 277:28411-28417. http://dx.doi.org/10.1074/jbc.M202807200.

48. Huda KA, Guo L, Haga S, Murata H, Ogino T, Fukai M, Yagi T, Iwagaki H, Tanaka N, Ozaki M. Ex vivo adenoviral gene transfer of constitutively activated STAT3 reduces post-transplant liver injury and promotes regeneration in a $20 \%$ rat partial liver transplant model. Transpl Int. 2006; 19:415-423. http://dx.doi. org/10.1111/j.1432-2277.2006.00285.x.

49. Trepo C, Zoulim F, Alonso C, Petit MA, Pichoud C, Vitvitski L. Diagnostic markers of viral hepatitis B and C. Gut. 1993; 34:S20-S25.

50. Norambuena PA, Copeland JA, Krenkova P, Stambergova A, Macek M Jr. Diagnostic method validation: High resolution melting (HRM) of small amplicons genotyping for the most common variants in the MTHFR gene. Clin Biochem. 2009; 42:1308-1316. http://dx.doi.org/10.1016/j. clinbiochem.2009.04.015. 